\title{
Look at the patient-in sugar and infection
}

\author{
Sascha Tafelski (D), Claudia Spies and Irit Nachtigall \\ See related research by Krinsley and Preiser, http://www.ccforum.com/content/19/1/179
}

With great interest, we followed the recent publication [1] regarding glucose management. The observational study evaluates patients in a medical-surgical intensive care unit (ICU) and reports on associations between time in targeted blood glucose range (TIR) and ICU mortality. The authors defined a TIR of $70-140 \mathrm{mg} / \mathrm{dl}$ (local hospital policy). The observed association with mortality was limited to non-diabetic patients and this is highly relevant. The presence of diabetes seems to reduce a protective effect of intensive blood glucose management in non-diabetics. A protective effect related to an intrinsic non-glucose-regulating mechanism of insulin $[2,3]$ was discussed but could also be altered by insulin resistance. Here, HBA1c measured on ICU admission or other surrogates (e.g., C-peptide related to blood glucose) could serve as potent biomarkers to identify patients who may benefit from glucose management. Every observation is exploratory and it is impossible to draw conclusions on causality. Other interacting factors like quality of infection management are also strongly related to ICU survival [4], and patients with diabetes have an increased risk to develop severe infections [2]. Interestingly, the findings of Krinsley and Preiser [1] are in line with results from another study in surgical ICU patients [5]. When slightly different cutoffs for low TIR were used, this measurement was associated with ICU mortality (odds ratio $=3.69, P=0.013$ ) for patients with lower achieved quality in blood glucose management [5].

In contrast to most published guidelines, future recommendations may need to include individualized algorithms (e.g., for patients with and patients without diabetes mellitus) [2]. In this context, we agree with the authors that a single target range of blood glucose management in the ICU setting seems to be arbitrary and further studies are required to study individualized therapy algorithms in both the surgical and the non-surgical ICU setting.

\section{Abbreviations \\ ICU: intensive care unit; TIR: time in targeted blood glucose range. \\ Competing interests \\ The authors declare that they do not have any competing interests concerning the specific subject of this letter. Unrelated to this work, IN and ST received lecture fees from Roche $\mathrm{GmbH}$ (Mannheim, Germany) and Pfizer (New York, NY, USA) and CS received funding from Merck Sharp \& Dohme GmbH (Haar, Germany), AstraZeneca (London, UK), Bristol-Myers Squibb GmbH (München, Germany), Pfizer, and Fresenius Kabi (Bad Homburg, Germany).}

\section{Authors' contributions}

ST and IN drafted the manuscript and CS revised it critically. All authors contributed to the conception and initiation of this work and read and approved the final manuscript.

Published online: 30 December 2015

\section{References}

1. Krinsley JS, Preiser JC. Time in blood glucose range 70 to $140 \mathrm{mg} / \mathrm{dl}>80 \%$ is strongly associated with increased survival in non-diabetic critically ill adults. Crit Care. 2015;19:179.

2. Siegelaar SE, Devries JH, Hoekstra JB. Patients with diabetes in the intensive care unit; not served by treatment, yet protected? Crit Care. 2010;14:126.

3. Van den Berghe G. How does blood glucose control with insulin save lives in intensive care? J Clin Invest. 2004;114:1187-95.

4. Nachtigall I, Tafelski S, Deja M, Halle E, Grebe MC, Tamarkin A, et al. Longterm effect of computer-assisted decision support for antibiotic treatment in critically ill patients: a prospective 'before/after' cohort study. BMJ Open. 2014;4:e005370.

5. Nachtigall I, Tafelski S, Tamarkin A, Rothbart A, Lange M, Wegener F, et al. Effect of blood-sugar limitation on intensive care mortality: intragroup evaluation. J Int Med Res. 2015;43:560-72.

\footnotetext{
* Correspondence: sascha.tafelski@charite.de

Department of Anaesthesiology and Intensive Care,

Charité-Universitaetsmedizin Berlin, Campus Charité Mitte and Campus

Virchow-Klinikum, Augustenburger Platz 1, 13353 Berlin, Germany
}

(C) 2015 Tafelski et al. Open Access This article is distributed under the terms of the Creative Commons Attribution 4.0 International License (http://creativecommons.org/licenses/by/4.0/), which permits unrestricted use, distribution, and reproduction in any medium, provided you give appropriate credit to the original author(s) and the source, provide a link to the Creative Commons license, and indicate if changes were made. The Creative Commons Public Domain Dedication waiver (http://creativecommons.org/publicdomain/zero/1.0/) applies to the data made available in this article, unless otherwise stated. 